\title{
Sintering Behaviour of Calcium Phosphate Based Powders prepared by Extraction Method
}

\author{
${ }^{* 1}$ Fatih Çalışkan, ${ }^{2}$ Serdar Gökhan Akça, ${ }^{3}$ Zafer Tatlı \\ ${ }^{1,3}$ Sakarya Uygulamalı Bilimler Üniversitesi, Esentepe Kampüsü, Sakarya, Türkiye \\ ${ }^{2}$ Turkish Airlines, Department of Aircraft Line Maintenance Management-Mechanical, İstanbul, Turkey
}

\begin{abstract}
Hydroxyapatite (HA) is widely used in biomedical implant applications, due to its bioactive, biodegradable and osteoconductive properties. The fabrication of HA by chemical routes is fairly complicated. Extraction of HA from the bovine bone is economic and bio compatible and besides it is easy to obtain. The HA extracted from the bovine bone have most properties of the origin bone. In addition to this, bone grafting potential is better than HA produced by chemical route.

The aim of this work is to understand sintering/densification behavior of HA produced from bovine bone (by Archimedes' principle kit), the microstructure of the sintered bodies (by SEM-EDS) and their mechanical properties (hardness and fractured toughness). Densifications of compact HA samples from natural bone with and without additive were investigated. Phase identification of the raw cow bone and sintered compacts were determined by X-ray diffraction technique.
\end{abstract}

Keywords: Hydroxyapatite, densification, sintering, bioceramic, powder process

\section{Giriş}

A significant proportion of biomaterials research has focused on bioceramics for over five decades as an alternative to implants to overcome their limited biocompatibility. This is especially visible in orthopedic applications where bioceramics can be found in almost every area of the skeletal system [1]. Orthopaedic researches has been increased on materials that may enhance bone regeneration in order to avoid skeletal repair complications [2].

The bioceramics interact with human biological system in the acceptable harm limits to the body [3]. Especially, hydroxyapatite, $\mathrm{Ca} 5(\mathrm{PO} 4) 3 \mathrm{OH}$, has been used since 1990 as coating on the prostheses of e.g. hips, knees, teeth in order to enhance its biointegration to a bone. The coatings have been deposited mainly by plasma spraying, chosen because of high deposition rate and low cost. On the other hand, there is a wealth of different deposition processes that can compete with plasma spraying if a particular coating property should be enhanced [4,5] Calcium hydroxyapatite is the main mineral component of bone tissue and teeth [6]. Hydroxyapatite (HA) is a naturally occurring form of calcium apatite [7]. Hydroxyapatite mineral (HA), $\mathrm{Ca}_{10}\left(\mathrm{PO}_{4}\right)_{6}(\mathrm{OH})_{2}$, is widely used to produce highly biocompatible ceramic materials for orthopaedic and dental applications [8].

Hydroxyapatite and tricalcium phosphate are the most popular calcium phosphate compounds as

*Corresponding author: Address: Faculty of Technology, Department of Metallurgical and Materials Engineering, Sakarya University of Applied Sciences, 54187, Sakarya TURKEY. E-mail address: fcaliskan@sakarya.edu.tr, Phone: +902642956501 
bone grafting materials in hard tissue parts and as candidate material for bone tissue implant applications, due to their excellent biocompatibility, ability to promote cellular functions and expressions, and osteoconductivity [9]. The chemical composition of HA can be easily changed while maintaining their biological activity and biocompatibility but improving their mechanical properties like tensile strength or impact resistance [10]. It has been available clinically for use in dentistry and medicine in recent years due to its excellent biocompatibility and osteoconduction $[11,12]$. Some research has revealed that the properties of HAp can be changed by modifying the composition through ionic substitutions [13].

The aim of this study is to investigate sinterability of HAp powders synthesised from bovine bone. It is well known that while chemical routes for HAp powder production are expensive, HAp powder can be synthesised from utilizing easily obtainable natural raw materials of relatively low cost. In addition, there are limited investigations on sinterability of the natural produced HAp powder. Grain morphology can be altered with changing production routes. Thus, it is hard to sinter HAp produced from bovine bone.

\section{Experimental}

Bovine bone was used as a raw material which was extracted from femur bone of cow with the age 2 years. The bone was crashed into small pieces and was cleaned and boiled up in water. Following process is burning out of organic matters (proteins and fats) by firing with the use of fire with high energy. After that, removing of the remains was carried out by heating at $900^{\circ} \mathrm{C}$ for $2 \mathrm{~h}$. The result product was milled using jet milling and sieved to ensure $>30$ micron. The powder was then uniaxially pressed into a cylindrical mould under $80 \mathrm{MPa}$ to obtain green samples. The green bodies were presurelessly sintered at different temperatures in the ranges from $1100^{\circ} \mathrm{C}$ to $1250^{\circ} \mathrm{C}$ for $0.5-2 \mathrm{~h}$ in air atmosphere.

Scanning electron microscopy was performed to reveal densification level and bone structure. EDS Elemental analyses of the HAp powder and femur bone of cow (raw material) were carried out to determine elements in the product. The densities of the sintered samples were measured by using Archimedes' principle method.

\section{Results and Discussion}

\subsection{Extraction of Hydroxyapatite Powder from Bovine Bone}

Hydroxyapatite powder was extracted from bovine bone and it has white color and reduced particle size. While the femur bone of cow has bone color before process, the color of raw material was changed to white after all burning out. The produced hydroxyapatite powders can be shown in Fig 1. Particle size of HAp powder is dominantly under $1 \mu \mathrm{m}$ and has homogeneous size distribution. EDS analysis of the produced powder was showed that it contained $\mathrm{Ca}, \mathrm{P}, \mathrm{Mg}, \mathrm{Na}$, $\mathrm{Fe}, \mathrm{O}, \mathrm{C}$. It is well known that elemental composition of the human bone tissue contains $\mathrm{Ca}, \mathrm{P}$, $\mathrm{Mg}, \mathrm{Al}, \mathrm{Na}, \mathrm{Si}, \mathrm{C}, \mathrm{Cl}, \mathrm{Fe}, \mathrm{O}$ elements. 


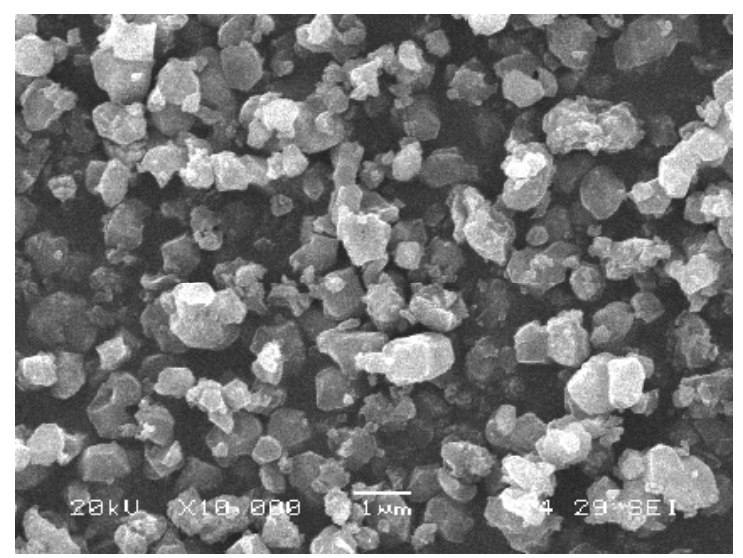

Figure 1. SEM micrograph of HAp powders (from bovine bone)

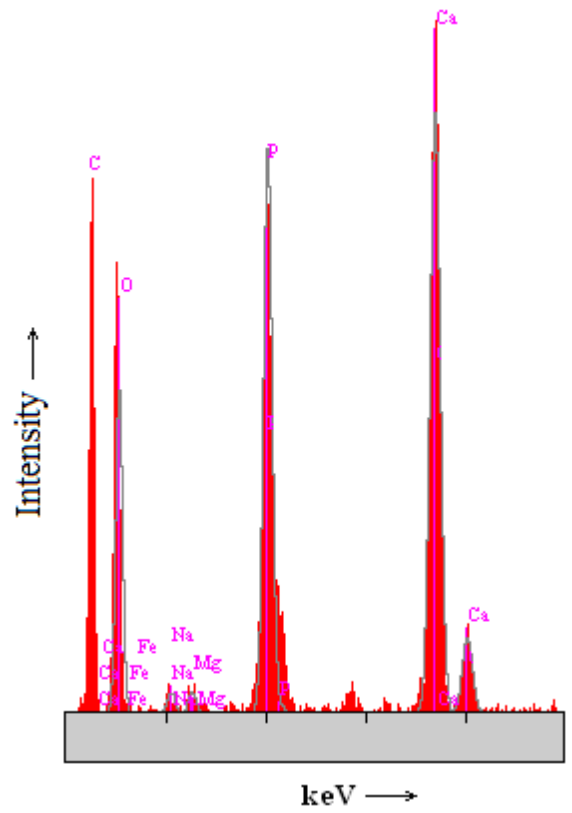

Figure 2. EDS analysis for HAp powders in Figure 1

\subsection{Sinterability of the HAp powder extracted from bovine bone}

\subsubsection{Densification behaviour}

The HAp compacts which were extracted from bovine bone without any additive were pressureless sintered at temperatures between 1100 and $1300^{\circ} \mathrm{C}$ for the periods of $30-120$ minutes shown in Table 1. As can be seen, the density of the pressureless sintered samples increased with sintering temperature. This was true up to $1250^{\circ} \mathrm{C}$. After this dwelling time, density value slightly decreased. This may be due to stability of HAp phase can lose at longer time and higher temperatures. The highest density $-3.11 \mathrm{~g} / \mathrm{cm} 3\left(98.5 \%\right.$ R.D.) was achieved at $1250^{\circ} \mathrm{C}$ for $90 \mathrm{~min}$. The lowest density $-2.84 \mathrm{~g} / \mathrm{cm} 3$ (89\% R.D.) was seen for a sample sintered at $1100^{\circ} \mathrm{C}$ for 30 
min. When increasing sintering temperature and dwelling time, the sintering process produces less porous samples.

Table 1. Density values for the sintered HAp samples

\begin{tabular}{|c|c|c|c|c|}
\hline \multirow{2}{*}{$30 \mathrm{~min}$} & \multicolumn{4}{|c|}{ Density $\left(\mathbf{g ~ c m}^{-3} \mathbf{)}\right.$} \\
\cline { 2 - 5 } & 1100 ○C & 1150 ○C & 1200 ○C & 1250 ○C \\
\hline $60 \mathrm{~min}$ & 2.84 & 2.87 & 3.00 & 3.03 \\
\hline $90 \mathrm{~min}$ & 2.89 & 2.91 & 3.01 & 3.07 \\
\hline $120 \mathrm{~min}$ & 2.92 & 2.97 & 3.05 & 3.11 \\
\hline
\end{tabular}

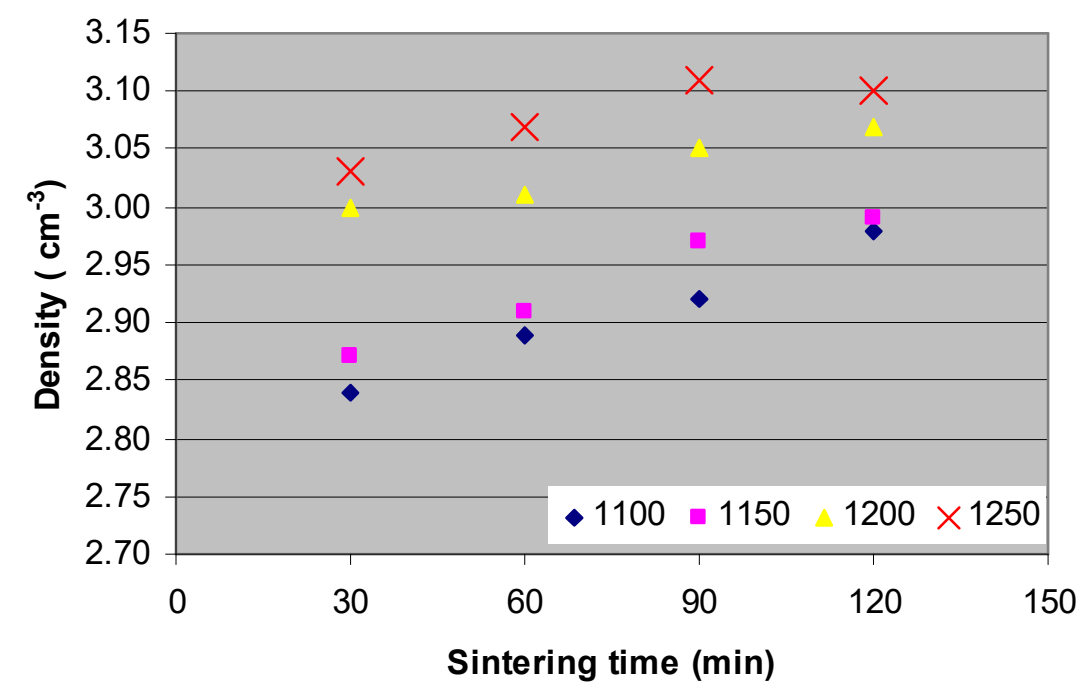

Figure 3. Densities of the sintered samples at the range between $1100-1250^{\circ} \mathrm{C}$

\subsubsection{General microstructural and elemental analysis}

SEM micrograph of original cow bone is seen in Figure 4. Fig 5 showed that elemental composition of cow bone composed of $\mathrm{Ca}, \mathrm{P}, \mathrm{Mg}, \mathrm{Na}, \mathrm{Si}, \mathrm{Fe}, \mathrm{O}, \mathrm{C}$. Figure 6 showed that the sintered sample at $1250^{\circ} \mathrm{C}$ for $90 \mathrm{~min}$ had nearly pore-free and gave a dense microstructure. In Figure 7, elemental composition of HAp sample is like $\mathrm{Ca}, \mathrm{P}, \mathrm{Mg}, \mathrm{Na}, \mathrm{C}$ and $\mathrm{O}$. The elemental composition difference between the sintered sample and cow bone is $\mathrm{Si}, \mathrm{C}$ and $\mathrm{Fe}$. This change can be due to the elevated temperature process. Si melting temperature is relatively lower. $\mathrm{C}$ can be unstable after $800^{\circ} \mathrm{C}$. All of them can cause the change being the mentioned above. 


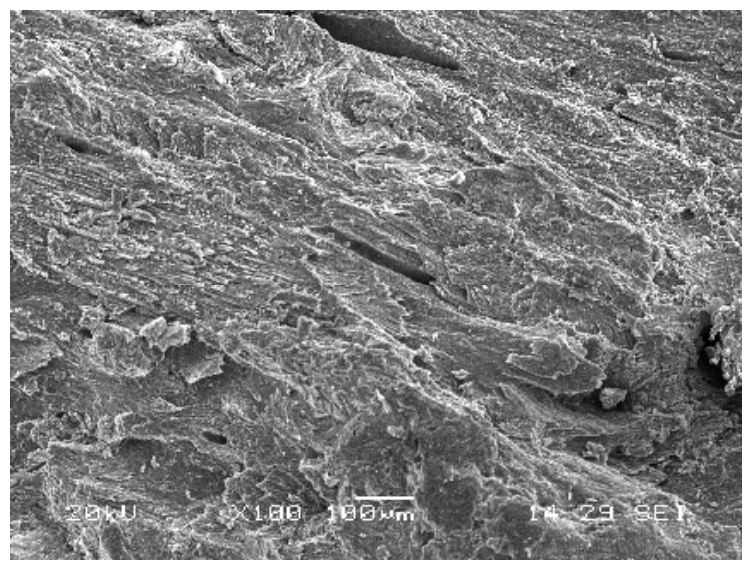

Figure 4. SEM micrograph for cow bone used as a raw material before firing

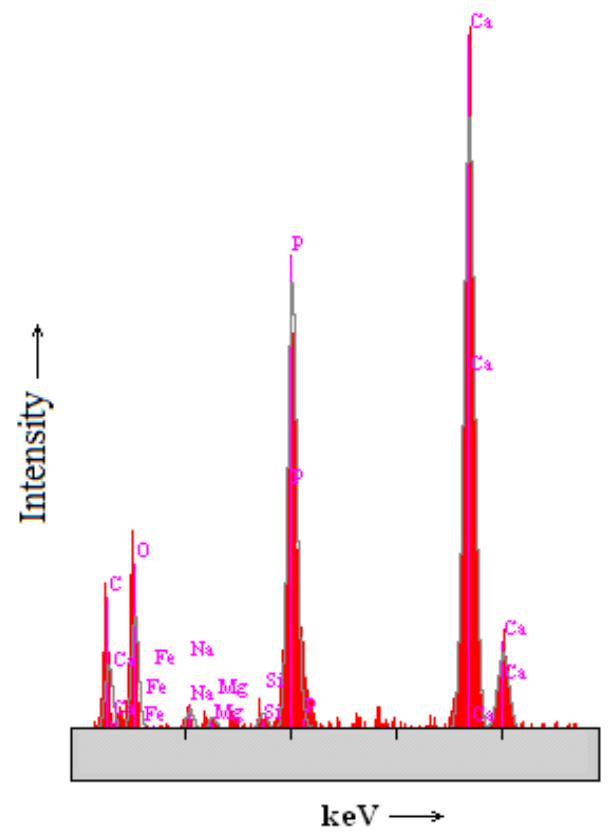

Figure 5. EDS analysis for cow bone before firing in Figure 4

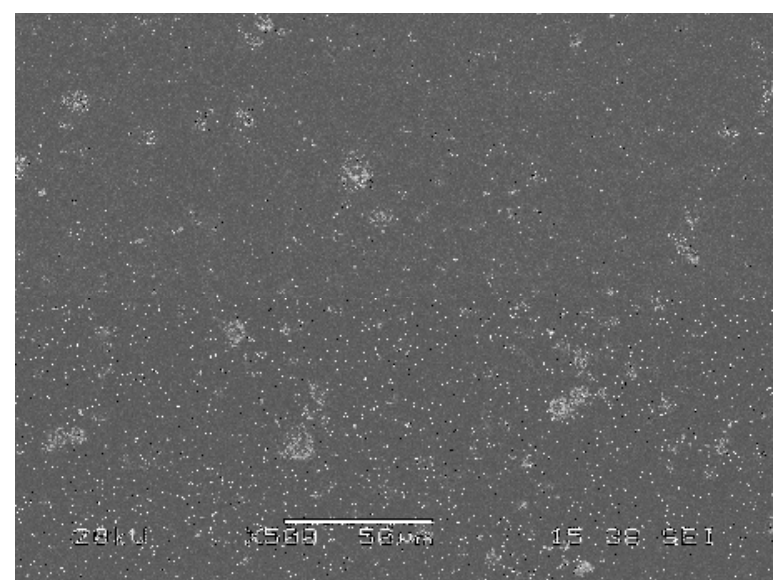

Figure 6. HAp sample presureless sintered at $1250^{\circ} \mathrm{C}$ for $90 \mathrm{~min}$ 


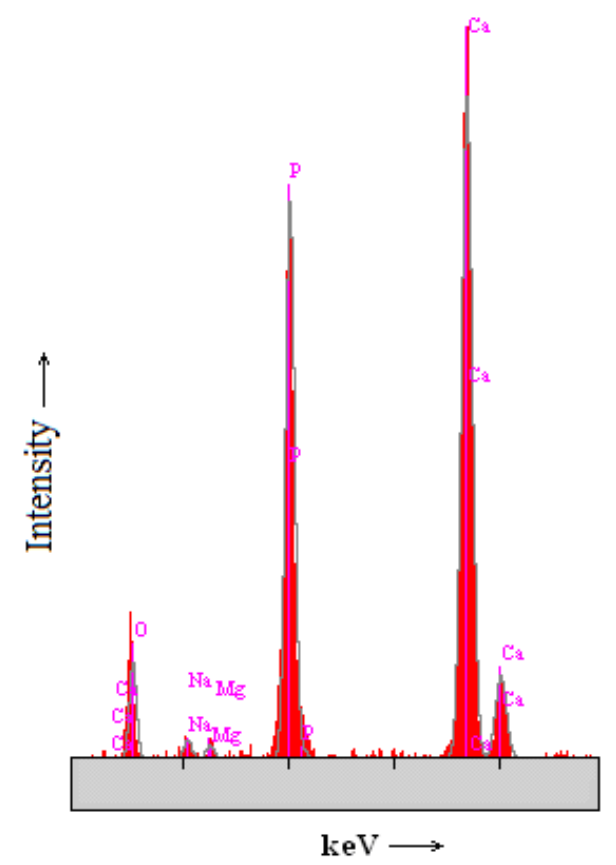

Figure 7. EDS analysis of HAp sample in Fig 6

\section{Conclusion}

These work revealed that production of hydroxyapatite powder with the use of natural raw materials are practicable. As well as, fabrication of HAp powder by this process is both inexpensive and is similar to human bone in terms of chemical composition. The other important point of this study is the obtaining of bulk HAp parts. HAp powders without any sintering aid was successfully presureless sintered and was achieved high dense structure. To summarize, production of powder and bulk HAp can be carried out with cheap raw material and easy process, and with the use of presureless sintering being inexpensive method, respectively.

\section{Acknowledgment}

This study was financially supported by Sakarya University Commissions for Scientific Research Projects within the context of "BAP-2012-09-08-004" numbered project.

\section{Referanslar}

[1] P. Mulinti, et al., Hemocompatibility of Biomaterials for Clinical Applications, 2018].

[2] Ito K, Yamada Y, Nagasaka T, Baba S, Ueda M. Osteogenic potential of injectable tissueengineered bone: a comparison among autogenous bone, bone substitute (Bio-oss), plateletrich plasma, and tissue-engineered bone with respect to their mechanical properties and histological findings. J Biomed Mater Res A 2005;73:63-72.]

[3] d'Haese R., Pawlowski L., Bigan M., et al., Phase evolution of hydroxapatite coatings 
suspension plasma sprayed using variable parameters in simulated body fluid, Surface \& Coatings Technology 204 (2010) 1236-1246

[4] Williams D.F., Biomaterials 29 (2008) 2941.

[5] Yang, Y. Kim, K.-H. K.-H. Ong, J.L., Biomaterials 26 (2005) 327.

[6] Elliott JC. Structure and chemistry of the apatites and other calcium orthophosphates.In: Studies in inorganic chemistry, vol. 18. Amsterdam: Elsevier;1994..

[7] Czarnowska, E. Zajaczkowska, A. . Godlewski, M.M., Mroz, W., J. Nanosci.Nanotechnol. 8 (2008) 1.

[8] LeGeros R.Z., in: P.W. Brown, B. Constanz (Eds.), Hydroxyapatite and Related Materials, CRC Press, Boca Raton, 1994, pp. 3-28.[4] R.Z. LeGeros, Calcium Phosphates in Oral Biology and Medicine, Karger, Basel,1991

[9] Cacciotti, I., et al. Mg-substituted hydroxyapatite nanopowders: Synthesis, thermal stability and sintering behaviour, Journal of the European Ceramic Society 29 (2009) 2969-2978

[10] Chang, E., Chang, W.J., Yang, C.Y., Mater. Sci. Mater. Med. 8 (1997) 193

[11] Suchanek W., Yoshimura M., Processing and properties of hydroxyapatite-based biomaterials as hard tissue replacement implants. J Mater Res 1998;13:94-117.

[12] Ming-Jie J., Xiao-Xiang W., Electrolytic deposition of magnesium-substituted hydroxyapatite crystals on titanium substrate, Materials Letters 63 (2009) 2286-2289

[13] LeGeros RZ., Properties of osteoconductive biomaterials: calcium phosphates. Clin Orthop Relat Res 2002;395:81-9. 